\title{
Double Radiofrequency Ablation with Metal Stent Placement for Refractory Benign Biliary and Pancreatic Duct Strictures
}

Tadahisa Inoue, Rena Kitano, Kiyoaki Ito, Masashi Yoneda

Department of Gastroenterology, Aichi Medical University, Nagakute, Aichi, Japan
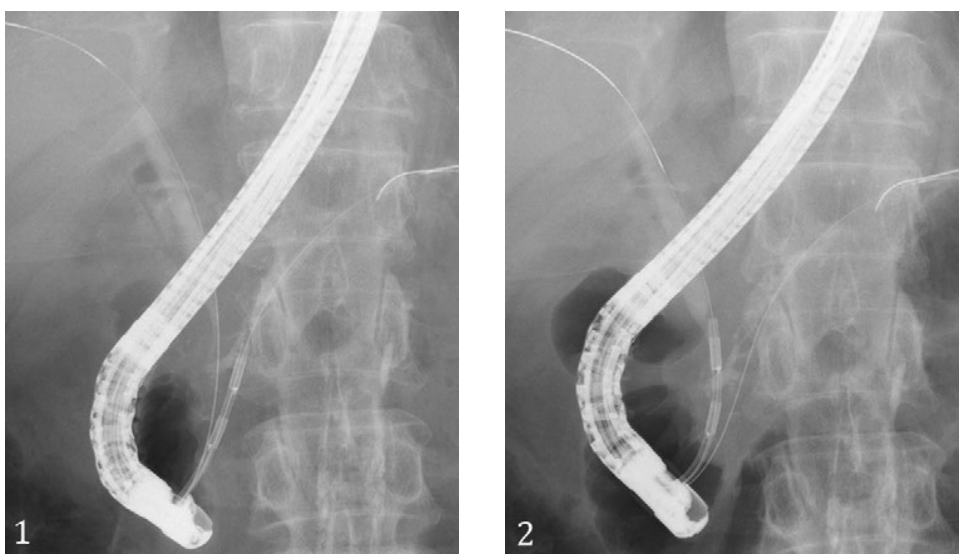

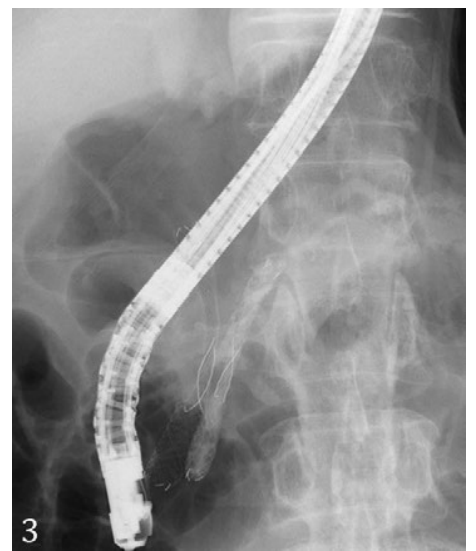

Endoscopic radiofrequency ablation (RFA) is a promising option for local control of malignant biliary strictures [1]. However, to the best of our knowledge, evidence of RFA for benign biliary strictures is very limited, and the use of RFA for benign pancreatic duct strictures has not been reported. Herein, we report a case of double RFA combined with metal stent placement for refractory benign biliary and pancreatic duct strictures.

A 50-year old male with alcoholic chronic pancreatitis developed recurrent jaundice and recurrent acute pancreatitis due to biliary and pancreatic duct strictures. Both strictures had been previously treated four times over 3 years by balloon dilation and/or temporary plastic or metal stent placement, but the symptomatic strictures recurred. Therefore, we performed endoscopic RFA to achieve long-term resolution of the strictures. After the insertion of a duodenoscope and two guidewires into the pancreatic duct and bile duct, RFA was performed for the pancreatic head duct stricture for 90 seconds at 7 watts power using a Habib EndoHPB catheter (Boston Scientific, Marlborough, MA) (Fig. 1). Subsequently, RFA was performed for the lower bile duct stricture for 90 seconds at 7 watts power (Fig. 2). After RFA, two fully covered metal stents each (BONASTENT M-Intraductal; Standard Sci-Tech Inc., Seoul, Korea) were placed in the pancreatic duct $(8 \times 50 \mathrm{~mm})$ and bile duct $(10 \times 60 \mathrm{~mm})$, across the strictures and duodenal papilla (Fig. 3). No procedure-related adverse events occurred. Three months later, these stents were removed, and no recurrence was observed after stent removal during the follow-up period (2 years).

RFA can alter the fibrous scar tissue, thus rendering further endoscopic therapy more efficacious in patients with benign strictures [1-2]. However, long-term outcomes are still uncertain, especially for pancreatic duct strictures. Thus, future investigations are warranted to further evaluate the efficacy of RFA for benign strictures.

Corresponding author: Tadahisa Inoue, tinoue-tag@umin.ac.jp

Conflicts of interest: T.I. received honoraria from Boston Scientific Japan and Japan Lifeline Co., Ltd. The other authors disclose no financial relationships relevant to this publication.

\section{REFERENCES}

1. Larghi A, Rimbaş M, Tringali A, Boškoski I, Rizzatti G, Costamagna G. Endoscopic radiofrequency biliary ablation treatment: A comprehensive review. Dig Endosc 2019;31:245-255. doi:10.1111/den.13298

2. Hu B, Gao DJ, Wu J, Wang TT, Yang XM, Ye X. Intraductal radiofrequency ablation for refractory benign biliary stricture: pilot feasibility study. Dig Endosc 2014;26:581-585. doi:10.1111/ den. 12225 